\title{
Change or stability in educational inequalities? Educational mobility and school effects in the context of a major urban policy
}

\author{
Gijs Custers $^{\mathrm{a}}$, Marjolijn Das ${ }^{\mathrm{ab}}$ and Godfried Engbersen ${ }^{\mathrm{a}}$ \\ ${ }^{a}$ Department of Public Administration and Sociology, Erasmus University, Rotterdam, the Netherlands \\ ${ }^{b}$ Statistics Netherlands, the Hague, the Netherlands
}

\begin{abstract}
The National Program Rotterdam South is a large-scale ambitious Dutch urban policy that aims to increase educational attainment amongst disadvantaged children in one of the poorest areas in the Netherlands. This study investigates to what extent inequality in educational attainment based on parental education has changed during the first period of this program. We further examine to what extent area and school characteristics affect educational attainment. Register data on the individual, school and area level were employed to study these issues. We find that the effect of parental education on secondary school attainment has been stable since the start of the program, indicating inequality has not decreased in the context of the program. Furthermore, several school characteristics, including socioeconomic status and retention rate, were relevant in explaining differences in educational attainment. We discuss how our findings relate to the allocation of policy means.
\end{abstract}

\section{Keywords}

Educational attainment; educational inequality; neighbourhood effects; school effects; urban policy 


\section{Introduction}

Inequality in educational attainment between children from different backgrounds is persistent and is frequently linked to the neighbourhood and school context (Nieuwenhuis and Hooimeijer, 2016). Different educational policies have been developed to address these inequalities. In this study we investigate whether inequality in educational opportunity has been reduced in the context of an ambitious urban policy in one of the poorest areas of the Netherlands. This policy is known as the National Program Rotterdam South (Nationaal Programma Rotterdam Zuid: NPRZ) and has the aim of raising the socioeconomic level of Rotterdam South in a period of 20 years, between 2011 and 2031, to the average level of the four largest cities in the Netherlands (Municipality of Rotterdam, 2011). The idea behind the program is that growing up in Rotterdam South provides a barrier to social mobility for children from disadvantaged backgrounds and that structural and innovative policies are needed to break the cycle of poverty. Multiple schools in Rotterdam South therefore have an extended school week, which is expected to lead to better educational outcomes among disadvantaged children.

This study adds to the literature on educational inequality in the urban context in two ways. First, it is well known that in urban areas inequality in educational attainment is high due to large population differences in terms of social class, ethnicity and household structure (Butler and Hamnett, 2007). This high level of inequality is likely to be exacerbated by school segregation in the Dutch educational landscape (see Boterman, 2019), because children tend to perform worse in schools where disadvantage is concentrated (Karsten et al., 2006;

Kuyvenhoven and Boterman, 2020; Thrupp et al., 2002). Yet, there is little research into how this inequality has developed in recent decades, meaning it is unclear how the effect of parental education on children's educational attainment has evolved under these urban conditions. Some evidence indicates that the effect of socioeconomic background is stable (Timmermans et al., 2018), but this has not been investigated for the urban context. By studying trends in the effect of parental education on children's educational attainment we shed more light on this issue and moreover, our study provides a first insight into what an ambitious policy like the NPRZ might achieve to improve educational opportunities for disadvantaged children.

Second, the policy targets about 30 primary schools in Rotterdam South under the assumption that living in this area negatively influences educational mobility and that any 
inequality in educational attainment should be addressed at the school level. This approach raises the question to what extent social processes at the school level account for the presumed negative effects of living in a poor area. A growing body of literature investigates how the school and neighbourhood context are related and shows that especially school characteristics are important in explaining differences in educational outcomes (e.g. Kauppinen, 2008; Kuyvenhoven and Boterman, 2020; Sykes and Musterd, 2011). We contribute to this literature by investigating to what extent the characteristics of NPRZ schools explain the relation between living in a poor area and educational attainment, thereby focusing on the role of school socioeconomic status (SES). ${ }^{1}$ We also discuss to what extent area poverty can be used as an indicator for the allocation of educational policy.

Our central research questions in this study are: to what extent has the effect of parental education on children's educational attainment changed in the context of the NPRZ? And to what extent do school characteristics play a role in this context? We will first discuss the key elements of the NPRZ and how it aims to reduce inequality in educational opportunity. Next, we discuss the role of area and school effects in the context of the NPRZ. In our analysis we use register data on the individual, school and area level for the Rotterdam population in the period before and after the start of the NPRZ (between 2008-2020). We investigate the association between parental level of education and children's level of education three years after primary school, at age 15. Multilevel analyses were employed to investigate to what extent this association depends on area and school characteristics.

\section{The National Program Rotterdam South and educational mobility}

Rotterdam South constitutes the part of the city located south of the New Meuse river and has historically developed as an area with a high level of poverty. This poverty concentration can be attributed to the cheap housing supply, built for harbour workers in the $20^{\text {th }}$ century, and the immigration of several migrant groups since the 1960s (see Custers, 2021). In 2011, a government commission concluded that the levels of disadvantage in Rotterdam South were of 'unDutch' proportions and that a long-term plan was needed to tackle these social issues structurally (Municipality of Rotterdam, 2011). The NPRZ is unique because national funds are 
directed toward a specific urban area. The scope of the program in terms of duration (20 years), funding and stakeholder involvement is incomparable to any other Dutch urban policy.

The NPRZ includes three 'pillars': work, housing and education. The underlying principle is that stakeholders (e.g. the municipality, housing corporations, employers, schools, local councils) collaboratively execute different subprograms within these three domains. Although the program targets the whole of Rotterdam South $( \pm 200,000$ inhabitants), a substantial number of resources is allocated to seven so-called 'focus' neighbourhoods $( \pm 80,000$ inhabitants) - see Supplemental Material for a map with the location of the focus neighbourhoods. These neighbourhoods have been designated as the most impoverished parts in terms of employment, housing supply and education.

Our focus in this paper is on the primary school interventions in these neighbourhoods and how they relate to trends in educational mobility and school effects. The interventions are modelled after the Harlem Children's Zone, a social program in Harlem, New York that has been successful in increasing school achievement among poor and mostly black children (Dobbie and Fryer, 2011). The primary schools in the focus neighbourhoods are therefore known as the NPRZ Children's Zone. The two main interventions in the NPRZ Children's Zone are: increased care support for parents and extended school time. ${ }^{2}$ The extended school time includes six to ten hours of extra schooling per week with the official goal to contribute to "good educational results, broad education and social-emotional development of children in the Children's Zone" (Kruiter et al., 2020: 7). Schools can freely choose the number of hours extra per week, provided this is somewhere between six and ten hours, and what activities they organise during this extra time. $^{3}$ Activities vary from homework assistance to cultural, sports and curricular activities. Since most schools do not have the capacity to organise these extra activities themselves, external providers are hired to do so. Furthermore, the NPRZ also aims to attract 'excellent' teachers to the schools in Children's Zone, although based on policy documents it is not clear how this will be achieved (e.g. NPRZ, 2012).

Besides the official goal of broad educational development, the interventions also have the informal goal to 'keep children of the street' (Kruiter et al., 2020). There seems to be consensus among stakeholders that the 'street', which can be seen as a neighbourhood process, has a negative influence on the educational development of children, because the perception is that the 
habitus formed on the street opposes the culture of learning at schools (el Hadioui, 2011; cf. Carter, 2003).

The interventions target schools in the focus neighbourhoods in Rotterdam South, where most of the student population comes from either low or middle-educated families. As children from these families are expected to perform better in school, the overall effect of parental education on children's educational attainment should decrease in Rotterdam South. Our first hypothesis therefore reads: the effect of parental education on children's secondary school track in Rotterdam South has become weaker after the start of the NPRZ (H1).

There are, however, several reasons why this hypothesis might not be supported. First, it has been questioned whether the extended school time will reduce inequality in educational attainment (Dol et al., 2019). A systematic review of this intervention indicates that evidence for causal effects is limited and that its effectiveness depends on implementation (Patall et al., 2010). The only Dutch study that investigated the effect of an extended day program shows no effect at all (Meyer and van Klaveren, 2013). Furthermore, within the NPRZ it is not clearly formulated how the extended school time should contribute to better educational outcomes for disadvantaged children, which is reflected in comments by involved stakeholders who doubt whether the extended school time increases educational performance (see Kruiter et al., 2020).

Second, concurrently with the NPRZ period a national 'crisis' has developed involving a lack of available qualified primary school teachers (Inspectorate of Education, 2019). This teacher shortage particularly affects schools in urban areas with a large share of students with a migration background and low SES, which are considered challenging environments for teachers to work. It has been very difficult for schools in the NPRZ Children's Zone to attract skilled and experienced teachers, while this is considered a crucial element in making other Children's Zones succeed (Dobbie and Fryer, 2011). Thus, it is likely that instructional quality in classrooms has been negatively affected due to a lack of high-quality teachers.

Third, a large body of sociological literature documents that educational mobility between generations has been quite stable over a longer period (see Breen and Johnson, 2005). Timmermans et al. (2018) observe no changes in track recommendation bias based on parental education between mid-1990s and mid-2000s. ${ }^{4}$ Explanations for why the effect of parental education endures include genetic factors ${ }^{5}$ (Plomin et al., 2016), different educational choices of 
the higher educated (Breen and Goldthorpe, 1997), and potential pressure by higher educated parents on teachers to give higher track recommendations (Timmermans et al., 2018). A report by the Inspectorate of Education (2019) shows that the effect of parental education on teacher recommendation, after controlling for test performance, increased between 2009 and 2017 after a national policy change was implemented in 2014 that gives more weight to the teacher's judgement concerning the final track recommendation - see further below. Hence, in recent years parental education could have become more important in children's educational attainment.

\section{Neighbourhood and school effects}

A principal point of discussion concerning the NPRZ is how the financial means for policy interventions should be distributed (Dol et al., 2019). The focus neighbourhoods were chosen because they are considered the most disadvantaged places in the city by the NPRZ, yet the geography of Rotterdam shows that other neighbourhoods in the south, north and east also include large shares of vulnerable residents (Custers and Engbersen, 2021). There was also discussion within the program whether the interventions should be implemented at the neighbourhood level, for instance through welfare organizations, or at the school level (Kruiter et al., 2020). The NPRZ thus first selected the focus neighbourhoods and thereafter the interventions were implemented at the school level. This issue on implementation relates to an ongoing debate about how neighbourhood and school characteristics affect educational outcomes, including the relevance of different contextual levels and the associated mechanisms through which neighbourhood and school effects are transmitted (e.g. Leventhal and BrooksGunn, 2000; Nieuwenhuis and Hooimeijer, 2016). The school context can mediate effects of the neighbourhood, or might even reinforce them (Cook, 2003). For example, poor neighbourhoods and poor schools are generally assumed to negatively impact educational outcomes through mechanisms such as social contagion and negative socialization (Jencks and Mayer, 1990). When children live in poor neighbourhoods and attend poor schools, they might experience negative influences from both places, whereas such influences might cancel each other out for children that go to affluent schools but live in poor neighbourhoods. Distinguishing between these different contextual effects is especially relevant in the Netherlands with its school system 
of free choice, meaning children can attend schools outside their own neighbourhood (Karsten, 1994).

Empirical evidence on the relative effects of neighbourhoods and schools is equivocal, but most European studies show that neighbourhood effects on educational outcomes are mostly mediated through the school context (Brannstrom, 2008; Kauppinen, 2008; Kuyvenhoven and Boterman, 2020; Sykes and Musterd, 2011). These studies suggest that the school is a more important context for socialization and subsequent educational outcomes than the neighbourhood context, even though the two are obviously related. At the school level the social mechanisms are more explicit and numerous than in neighbourhoods (Johnson, 2008). Such school mechanisms may include peer group processes, the quality of classroom instruction and school organization (Thrupp et al., 2002). The NPRZ has a special position considering neighbourhood and school effects, since the selection of schools takes place at the area level - i.e., all schools in the focus neighbourhoods - while the interventions are implemented at the school level. We hypothesise that the negative effect of living in the focus neighbourhoods on children's secondary school track is mediated by school characteristics (H2).

\section{The Dutch educational system}

A brief explanation of the Dutch educational system serves to understand educational mobility in the urban context. Students enter primary school at age 4 . After 8 years, around age 12, they make the transition to secondary school, in which four tracks are available. Tracking thus occurs at an early age (van de Werfhorst and Mijs, 2010). Students receive an initial track recommendation in the final year of primary school and subsequently, students make a standardised test including math and language exercises. Teachers can adjust their recommendation to a lower or higher track advice based on test performance. ${ }^{6}$ The final teacher recommendation determines which track students will start in secondary school, although they are free to choose a lower track than recommended (but not a higher one). The following four tracks are available in secondary school:

- Practical education (PRO), 
- Pre-vocational education (VMBO), including four different levels ranging from basic to theoretical orientation,

- Senior general secondary education (HAVO),

- And pre-university education (VWO).

The PRO and VMBO tracks take four years to complete and provide access to different levels of vocational college (MBO). The HAVO track lasts five years and provides access to higher professional education (HBO). The VWO track is the highest-level track and is completed in 6 years, after which students can attend university (WO).

The transition from primary to secondary school is seen as decisive step that strongly determines life chances. However, in the first years of secondary school, students are often enrolled in so-called 'bridging classes' that consist of two or three different tracks, for instance $\mathrm{HAVO} / \mathrm{VWO}$ or VMBO/HAVO/VWO. This means that for many students the sorting into their final track is delayed until age 14-15, and mobility between tracks can still occur after initial track placement.

\section{Data and method}

Individual register data from the System of social statistical datasets (SSD) is used to investigate the effect of parental education over time and the influence of area and school context. The SSD combines data from different administrative sources in the Netherlands, such as the population register, educational institutions and the tax authority. Pseudonymised data is made available for scientific research by Statistics Netherlands, subject to legal and ethical restrictions. Our data covers the period 2008-2020, as 2008 is the first year in which data from school registers is available. We selected nine cohorts of students (2008/2009 - 2016/2017) that were in the final year of primary school and that resided and attended school in Rotterdam. Children who resided outside Rotterdam but attended school there, or vice versa, were thus excluded from the dataset. Children were linked to their parents, households, schools and area based on unique identifiers. The final dataset included 49,987 students nested in 209 schools and 1727 school-cohort combinations. 


\section{Individual level variables}

Secondary school track - the dependent variable is the secondary school track that children followed three years after primary school (around age 15). At that time, most children have been selected into tracks. Some students (9.4\%) did not have a single-track level after three years. For them, we obtained the track level four years after primary school. Our dependent variable thus includes the first observed reliable indicator of students' educational level at secondary school. We classified the track levels into four categories, which we subsequently transformed into ISLED scores (the International Standard Level of Education). This transformation of the dependent variable into a continuous scale of 0-100 increases its interpretability in an international context (Schröder and Ganzeboom, 2014). The following scores are included: lower pre-vocational education (LPV) (PRO/VMBO basis/kader, ISLED = 29.34), upper prevocational education (UPV) (VMBO gemengd/theoretisch, ISLED $=45.27)$, senior general secondary education (SGS) (HAVO, ISLED = 62.3) and pre-university education (VWO, ISLED $=71.92)$. Missing values (4.1\%, due to an unknown secondary school track, emigration or death of the student) were removed through listwise deletion.

Parental education - the highest level of education that either of the parents had achieved. Categories were coded into four dummy variables: lower educated (up to MBO level 2), middle educated (MBO level 2 and higher), higher professional (HBO) and university (WO). Since the number of missing values on parental education tends to be high in the SSD - registration is mostly lacking for (older) immigrants - we included an extra dummy variable to account for these missing values (12.9\% in total).

Control variables - we included several control variables to reduce the likelihood of omitted variable bias. These control variables include sex, age, ethnicity, household status, main household income source, disposable household income, household wealth, and years spent at the same primary school (see Table 1).

\section{School, area and cohort variables}

School SES - the SES level of primary schools was determined by a factor analysis of four variables: the share of low educated parents, the share of high educated parents (higher 
professional/university), the share of students in the lowest quartile of affluent households and the share of students in the highest quartile of affluent households. Household affluence is an indicator in the SSD that combines data on the income and wealth position of households. The factor analysis showed that one scale can be formed from these four variables (factor loadings $>.85$ ) and therefore a standardised factor score was calculated. Since the distribution was positively skewed - most children attend lower SES schools - the factor score was recoded into quintiles, including five equal groups from very low (1) to very high (5).

Two other variables on the school level were included that might explain educational attainment. ${ }^{7}$ School stability includes the average number of years students spent at a school. We assume that a lower student turnover results in better educational outcomes, since students are more comfortable and familiar with their school environment. School denomination is further measured by four categories: public, protestant, catholic and other.

NPRZ area - to investigate the differences between areas we adopt the NPRZ area classification. Three dummy variables measure whether children lived in the focus neighbourhoods (1), the other NPRZ area (2) or the rest of Rotterdam (3).

Cohort - the year in which students started the final year of primary school, including nine cohorts in total (2008/2009 - 2016/2017). These cohorts are included as dummy variables in the analysis.

Descriptive information about these variables can be found in Table 1. 
Table 1. Descriptive statistics

\begin{tabular}{|c|c|c|c|c|c|c|c|}
\hline & Mean & Sd. & Min. & Max. & $\begin{array}{l}\text { Mean focus } \\
\text { neighbourhoods }\end{array}$ & $\begin{array}{c}\text { Mean NPRZ } \\
\text { other }\end{array}$ & $\begin{array}{c}\text { Mean } \\
\text { Rotterdam } \\
\text { other }\end{array}$ \\
\hline ISLED 4 categories & 47.603 & 16.293 & & & 43.466 & 44.614 & 49.291 \\
\hline \multicolumn{8}{|l|}{ Education parents } \\
\hline Low & 0.318 & & 0 & 1 & 0.456 & 0.346 & 0.281 \\
\hline Middle & 0.318 & & 0 & 1 & 0.329 & 0.386 & 0.296 \\
\hline Higher professional & 0.116 & & 0 & 1 & 0.072 & 0.096 & 0.130 \\
\hline University & 0.120 & & 0 & 1 & 0.031 & 0.057 & 0.156 \\
\hline Missing & 0.129 & & 0 & 1 & 0.112 & 0.114 & 0.137 \\
\hline Female & 0.502 & & 0 & 1 & 0.510 & 0.500 & 0.501 \\
\hline Age & 11.528 & & & & 11.595 & 11.529 & 11.513 \\
\hline \multicolumn{8}{|l|}{ Ethnicity } \\
\hline Native Dutch & 0.378 & & 0 & 1 & 0.122 & 0.317 & 0.448 \\
\hline Moroccan & 0.139 & & 0 & 1 & 0.176 & 0.119 & 0.138 \\
\hline Turkish & 0.126 & & 0 & 1 & 0.300 & 0.104 & 0.097 \\
\hline Surinamese & 0.104 & & 0 & 1 & 0.118 & 0.138 & 0.092 \\
\hline Antillean & 0.046 & & 0 & 1 & 0.056 & 0.096 & 0.029 \\
\hline Cape Verdean & 0.031 & & 0 & 1 & 0.032 & 0.019 & 0.034 \\
\hline Former Yugoslavia & 0.015 & & 0 & 1 & 0.013 & 0.025 & 0.013 \\
\hline Pakistani & 0.012 & & 0 & 1 & 0.041 & 0.008 & 0.007 \\
\hline Other & 0.147 & & 0 & 1 & 0.141 & 0.174 & 0.141 \\
\hline \multicolumn{8}{|l|}{ Household status } \\
\hline Married couple & 0.569 & & 0 & 1 & 0.593 & 0.479 & 0.589 \\
\hline Unmarried couple & 0.121 & & 0 & 1 & 0.094 & 0.127 & 0.124 \\
\hline One parent household & 0.300 & & 0 & 1 & 0.300 & 0.379 & 0.277 \\
\hline Other household & 0.011 & & 0 & 1 & 0.013 & 0.015 & 0.010 \\
\hline \multicolumn{8}{|l|}{$\begin{array}{l}\text { Household's main } \\
\text { income source }\end{array}$} \\
\hline Wage employment & 0.600 & & 0 & 1 & 0.524 & 0.585 & 0.620 \\
\hline Social assistance & 0.240 & & 0 & 1 & 0.330 & 0.287 & 0.208 \\
\hline Self-employed & 0.114 & & 0 & 1 & 0.092 & 0.079 & 0.129 \\
\hline Other income source & 0.032 & & 0 & 1 & 0.041 & 0.032 & 0.030 \\
\hline Missing & 0.014 & & 0 & 1 & 0.013 & 0.016 & 0.013 \\
\hline $\begin{array}{l}\text { Disposable household } \\
\text { income (deciles) }\end{array}$ & 3.980 & 2.905 & 0 & 10 & 2.700 & 3.431 & 4.394 \\
\hline Missing Income & 0.024 & & 0 & 1 & 0.025 & 0.030 & 0.022 \\
\hline Wealth (deciles) & 3.708 & 2.605 & 0 & 10 & 2.931 & 3.163 & 4.020 \\
\hline Missing Wealth & 0.011 & & 0 & 1 & 0.012 & 0.015 & 0.010 \\
\hline \multicolumn{8}{|l|}{ Years at same school } \\
\hline 1-2 years & 0.095 & & 0 & 1 & 0.106 & 0.098 & 0.092 \\
\hline 3-4 years & 0.126 & & 0 & 1 & 0.147 & 0.137 & 0.118 \\
\hline 5-6 years & 0.111 & & 0 & 1 & 0.125 & 0.123 & 0.105 \\
\hline
\end{tabular}




\begin{tabular}{|c|c|c|c|c|c|c|c|}
\hline $7-8$ years & 0.562 & & 0 & 1 & 0.501 & 0.545 & 0.579 \\
\hline $9-10$ years & 0.106 & & 0 & 1 & 0.121 & 0.098 & 0.106 \\
\hline \multicolumn{8}{|l|}{ School SES } \\
\hline Very low & 0.200 & & 0 & 1 & 0.287 & 0.133 & 0.201 \\
\hline Low & 0.200 & & 0 & 1 & 0.416 & 0.357 & 0.112 \\
\hline Middle & 0.200 & & 0 & 1 & 0.240 & 0.332 & 0.155 \\
\hline High & 0.200 & & 0 & 1 & 0.033 & 0.118 & 0.257 \\
\hline Very high & 0.200 & & 0 & 1 & 0.023 & 0.060 & 0.275 \\
\hline School stability & 6.568 & 0.970 & & & 6.365 & 6.467 & 6.638 \\
\hline \multicolumn{8}{|l|}{ School denomination } \\
\hline Public & 0.351 & & 0 & 1 & 0.428 & 0.381 & 0.327 \\
\hline Protestant & 0.335 & & 0 & 1 & 0.344 & 0.340 & 0.332 \\
\hline Catholic & 0.240 & & 0 & 1 & 0.153 & 0.220 & 0.264 \\
\hline Other denomination & 0.074 & & 0 & 1 & 0.075 & 0.059 & 0.078 \\
\hline \multicolumn{8}{|l|}{$N P R Z$ area } \\
\hline Focus neighbourhoods & 0.138 & & 0 & 1 & & & \\
\hline NPRZ other & 0.189 & & 0 & 1 & & & \\
\hline Rotterdam other & 0.673 & & 0 & 1 & & & \\
\hline \multicolumn{8}{|l|}{ Cohort } \\
\hline $2008 / 2009$ & 0.096 & & 0 & 1 & 0.087 & 0.092 & 0.099 \\
\hline $2009 / 2010$ & 0.110 & & 0 & 1 & 0.116 & 0.113 & 0.108 \\
\hline $2010 / 2011$ & 0.114 & & 0 & 1 & 0.120 & 0.115 & 0.112 \\
\hline $2011 / 2012$ & 0.118 & & 0 & 1 & 0.119 & 0.118 & 0.117 \\
\hline $2012 / 2013$ & 0.113 & & 0 & 1 & 0.113 & 0.112 & 0.114 \\
\hline $2013 / 2014$ & 0.112 & & 0 & 1 & 0.105 & 0.105 & 0.115 \\
\hline $2014 / 2015$ & 0.113 & & 0 & 1 & 0.110 & 0.111 & 0.115 \\
\hline $2015 / 2016$ & 0.112 & & 0 & 1 & 0.119 & 0.117 & 0.110 \\
\hline $2016 / 2017$ & 0.112 & & 0 & 1 & 0.111 & 0.117 & 0.111 \\
\hline$N$ & 49,987 & & & & 6,897 & 9,449 & 33,641 \\
\hline
\end{tabular}

\section{Strategy of analysis}

We start our analysis with descriptive results on how large inequalities in educational attainment are between different areas in Rotterdam. Thereafter, we present linear multilevel models that we use to test our hypotheses. In these random intercept models student's characteristics (level 1) are nested within school-cohorts (level 2), which in turn are nested within schools (level 3). The 
variance components indicate to what extent these levels account for variation in the dependent variable. Based on the models we also checked multiple residual plots, which showed that assumptions of linearity were met. The models were estimated in R using the 'lme4' package.

An empty model (Model 0) is first estimated to calculate the variance proportions at different levels. In Model 1 we include the individual variables and cohorts. The latter are also part of the multilevel structure of the data. We add the NPRZ area variable in Model 2. The school variables are further included in Model 3 to investigate their effects and how they affect the relation between NPRZ area and secondary school track (hypothesis 2). We then split the data into Rotterdam South and Rotterdam-other. For both parts of the city, we investigate to what extent the effect of parental education on children's educational attainment has changed over time. We take the cohort 2012/2013 as the reference category, because most schools in the focus neighbourhoods started with the extended school time for the subsequent cohort. We thus expect no change in the effect or parental education up to 2012/2013 and a decrease of the effect thereafter in Rotterdam South (hypothesis 1). This change in effect size is estimated through interacting parental education with cohort (Model 4a and 4b).

\section{Results}

Table 1 shows the population differences between the focus neighbourhoods, the non-focus neighbourhoods in Rotterdam South (NPRZ-other) and the rest of Rotterdam (Rotterdam-other). The difference in ISLED score between the focus neighbourhoods and Rotterdam-other area is quite large (43.5 vs. 49.3). Furthermore, $79 \%$ of the parents in the focus neighbourhoods are either low (46\%) or middle educated (33\%), whereas this share is $73 \%$ in the NPRZ-other area (35\% and $39 \%)$ and $58 \%$ in the Rotterdam-other area (30\% and $28 \%$ ).

The first part of our multilevel analyses investigates to what extent the presumed negative effect of living in the focus neighbourhoods is mediated by school characteristics (hypothesis 2 , Table 2). Model 0 indicates how much of the variance in the dependent variable can be attributed to each level in the model. The largest part of the variance is on the individual (76\%) and the primary school level (23\%). ${ }^{8}$ The school level variance indicates substantial differences between primary schools in subsequent secondary school attainment. Yet, a large part of this variation is 
explained by differences in individual attributes (Model 1), since the school-level variance is reduced by $68 \%$ ((59.89-18.91)/59.89) by including the individual-level variables. Based on Model 2 we further observe that the effect of living in the focus neighbourhoods, compared to living in Rotterdam-other area, is non-significant, indicating that living in the focus neighbourhoods is not negatively related to educational attainment net of individual characteristics and between-school variation. The school-level variables in Model 3 on the other hand do explain some of the differences between students. School stability and school SES are both strongly positively related to subsequent secondary school attainment. A one-year increase in average student retention is associated with a 1.8 increase in ISLED-score. Attending a school with very high SES increases the ISLED score by 4.7 compared to attending a middle-SES school, whereas attending a very low SES school decreases the ISLED score by 2.1. Students at public schools have a 2.6 lower ISLED score than students on other schools. The explained variance on the school level further increases from 69\% (Model 2: (59.89-18.56)/59.89) to 90\% (Model 3: (59.89-5.82)/59.89). Regarding hypothesis 2, even though considerable school 'effects' exist there is no negative 'effect' of living in the focus neighbourhoods in the first place - note however that school level variance was already corrected for in Model 2. Based on these results we reject this mediation hypothesis. 
Table 2. Linear multilevel models including effects of individual, school and area characteristics on students' secondary school track at age 15/16 (ISLED scores)

\begin{tabular}{|c|c|c|c|c|}
\hline & Model 0 & Model 1 & Model 2 & Model 3 \\
\hline \multicolumn{5}{|c|}{ Cohort $($ ref. $=2012 / 2013)$} \\
\hline \multirow[t]{2}{*}{$2008 / 2009$} & & 0.482 & 0.480 & 0.475 \\
\hline & & $(-0.089,1.054)$ & $(-0.091,1.051)$ & $(-0.098,1.049)$ \\
\hline \multirow[t]{2}{*}{ 2009/2010 } & & 0.178 & 0.176 & 0.156 \\
\hline & & $(-0.370,0.725)$ & $(-0.372,0.723)$ & $(-0.394,0.706)$ \\
\hline \multirow[t]{2}{*}{$2010 / 2011$} & & -0.189 & -0.192 & -0.216 \\
\hline & & $(-0.728,0.349)$ & $(-0.730,0.347)$ & $(-0.757,0.325)$ \\
\hline \multirow[t]{2}{*}{$2011 / 2012$} & & -0.122 & -0.122 & -0.133 \\
\hline & & $(-0.657,0.412)$ & $(-0.657,0.412)$ & $(-0.670,0.404)$ \\
\hline \multirow[t]{2}{*}{$2013 / 2014$} & & -0.211 & -0.215 & -0.226 \\
\hline & & $(-0.753,0.331)$ & $(-0.758,0.327)$ & $(-0.771,0.319)$ \\
\hline \multirow[t]{2}{*}{$2014 / 2015$} & & -0.045 & -0.044 & -0.039 \\
\hline & & $(-0.587,0.497)$ & $(-0.586,0.498)$ & $(-0.583,0.505)$ \\
\hline \multirow[t]{2}{*}{$2015 / 2016$} & & 0.162 & 0.164 & 0.160 \\
\hline & & $(-0.381,0.706)$ & $(-0.380,0.708)$ & $(-0.386,0.706)$ \\
\hline \multirow[t]{2}{*}{$2016 / 2017$} & & 0.268 & 0.269 & 0.289 \\
\hline & & $(-0.278,0.814)$ & $(-0.277,0.815)$ & $(-0.259,0.837)$ \\
\hline \multicolumn{5}{|c|}{ Parental education (ref. $=$ Low) } \\
\hline \multirow[t]{2}{*}{ Middle } & & $2.543^{* * *}$ & $2.544^{* * *}$ & $2.519^{* * *}$ \\
\hline & & $(2.240,2.846)$ & $(2.242,2.847)$ & $(2.216,2.822)$ \\
\hline \multirow[t]{2}{*}{ Higher professional } & & $7.323^{* * *}$ & $7.323^{* * *}$ & $7.253^{* * *}$ \\
\hline & & $(6.887,7.759)$ & $(6.886,7.759)$ & $(6.817,7.689)$ \\
\hline \multirow[t]{2}{*}{ University } & & $11.090^{* * *}$ & $11.080^{* * *}$ & $10.980^{* * *}$ \\
\hline & & $(10.600,11.580)$ & $\begin{array}{c}(10.590 \\
11.570)\end{array}$ & $\begin{array}{c}(10.490 \\
11.470)\end{array}$ \\
\hline \multirow[t]{2}{*}{ Female } & & $1.087^{* * * *}$ & $1.086^{* * *}$ & $1.086^{* * *}$ \\
\hline & & $(0.861,1.313)$ & $(0.860,1.312)$ & $(0.860,1.312)$ \\
\hline \multirow[t]{2}{*}{ Age } & & $-3.036^{* * *}$ & $-3.037^{* * *}$ & $-3.033^{* * *}$ \\
\hline & & $(-3.251,-2.821)$ & $\begin{array}{c}(-3.252,- \\
2.822)\end{array}$ & $(-3.248,-2.818)$ \\
\hline \multicolumn{5}{|c|}{ Ethnicity (ref. $=$ Native Dutch) } \\
\hline \multirow[t]{2}{*}{ Moroccan } & & 0.400 & 0.393 & $0.595^{* *}$ \\
\hline & & $(-0.052,0.851)$ & $(-0.059,0.845)$ & $(0.142,1.047)$ \\
\hline \multirow[t]{2}{*}{ Turkish } & & $-0.990^{* * *}$ & $-0.993^{* * *}$ & $-0.799^{* * * *}$ \\
\hline & & $(-1.436,-0.544)$ & $\begin{array}{c}(-1.441,- \\
0.545)\end{array}$ & $(-1.246,-0.351)$ \\
\hline \multirow[t]{2}{*}{ Surinamese } & & $-0.577^{* *}$ & $-0.572^{* *}$ & $-0.433^{*}$ \\
\hline & & $(-1.010,-0.145)$ & $\begin{array}{c}(-1.004,- \\
0.139)\end{array}$ & $(-0.865,-0.001)$ \\
\hline \multirow[t]{2}{*}{ Antillean } & & $-2.473^{* * *}$ & $-2.463^{* * *}$ & $-2.347^{* * *}$ \\
\hline & & $(-3.074,-1.872)$ & $\begin{array}{c}(-3.064,- \\
1.862)\end{array}$ & $(-2.948,-1.746)$ \\
\hline Cape Verdean & & $-2.310^{* * *}$ & $-2.319^{* * * *}$ & $-2.160^{* * *}$ \\
\hline
\end{tabular}


Former Yugoslavia

Pakistani

Other

Household status (ref. = Married couple)

Unmarried couple

One parent household

Other household

Household's main income source (ref. = Wage)

Social assistance

Self-employed/managing director

Other income source

Disposable household income (deciles)

Wealth (deciles)

Years at same school (ref. $=1-2$ years)

3-4 years

5-6 years

7-8 years

9-10 years

NPRZ area (ref. $=$ Rotterdam

other)

NPRZ other

Focus neighbourhoods

$$
\begin{array}{ccc}
(-3.014,-1.606) & (-3.023,- & (-2.864,-1.455) \\
4.006^{* * *} & 1.614) & 4.135^{* * *} \\
(3.063,4.948) & (3.070,4.955) & (3.192,5.077) \\
1.616^{* *} & 1.616^{* * *} & 1.768^{* *} \\
(0.534,2.698) & (0.533,2.699) & (0.685,2.850) \\
2.911^{* * *} & 2.914^{* * *} & 3.009^{* * *} \\
(2.540,3.283) & (2.542,3.285) & (2.637,3.380)
\end{array}
$$

$-1.292^{* * *}$
$(-1.663,-0.920)$

$-1.289^{* * *}$

$-1.279^{* * *}$

$(-1.661,-$ $0.918)$

$(-1.650,-0.907)$

$-2.124^{* * *}$

$-2.121^{* * *}$

$-2.118^{* * *}$

$(-2.429,-1.819)$

$(-2.426,-$ 1.816)

$(-2.423,-1.813)$

$$
-3.323^{* * *}
$$

$-3.328^{* * *}$

$-3.305^{\text {*** }}$

$(-4.656,-1.990)$

$(-4.661,-$

1.995)

$(-4.638,-1.972)$

$$
-0.602^{* * *}
$$

$(-0.941,-0.262)$

0.159

$(-0.219,0.537)$

0.017

$(-0.756,0.790)$

$-0.603^{* * *}$

(-0.943, -

$0.264)$

0.160

$(-0.218,0.538)$

0.014

$(-0.759,0.787)$

$0.464^{* * *}$

$0.465^{\text {*** }}$

$-0.594^{* * *}$

$(-0.934,-0.254)$

$(0.405,0.524)$
$0.547^{* * *}$

$(0.405,0.524)$

$0.546^{* * *}$

0.124

$(-0.254,0.502)$

0.011

$(-0.762,0.784)$

$(0.495,0.598)$

(0.494, 0.598)

$0.454^{* * * *}$

(0.394, 0.513)

$0.540^{* * * *}$

$(0.488,0.592)$

$\begin{array}{ccc}0.500^{*} & 0.498^{*} & 0.430 \\ (0.008,0.991) & (0.007,0.990) & (-0.061,0.922) \\ 0.969^{* * *} & 0.969^{* * *} & 0.847^{* *} \\ (0.462,1.476) & (0.462,1.476) & (0.340,1.354) \\ 2.936^{* * *} & 2.937^{* * *} & 2.788^{* * *} \\ (2.513,3.359) & (2.514,3.360) & (2.364,3.212) \\ -3.308^{* * *} & -3.309^{* * *} & -3.447^{* * *} \\ (-3.847,-2.769) & (-3.848,- & (-3.987,-2.906)\end{array}$

$$
-0.780
$$

$-0.308$

$(-1.603,0.042)$

$(-1.001,0.384)$

$-0.589$

0.033 
School SES (ref. = Middle)

Very low

Low

High

Very high

School stability

School denomination (ref. $=$ Public)

Protestant

$(-0.187,1.538)$

$-0.269$

$(-1.277,0.739)$

$2.574^{* * *}$

Other denomination

Constant

$45.890^{* * * *}$

$(44.830,46.950)$

$\mathrm{N}$

Log Likelihood

Variance school level

Variance school-year level

Variance individual level
$(1.167,3.980)$

$42.540^{* * * *}$

(41.370, 43.710)

43.440) $\quad 43.710$

49,987

$-203,592$

18.56

$-198,804$

5.82

1.45

164.14

Note: Effects of dummy variables that account for missings (education parents, household income source, household income and wealth) not reported here. ${ }^{*} \mathrm{p}<0.05^{* *} \mathrm{p}<0.01{ }^{* * *} \mathrm{p}<0.001$

Model 3 shows that school SES is an important predictor. We plotted the distribution of students by school SES and NPRZ area in Figure 2. This figure shows that most children in the focus neighbourhoods attend a school where the SES level is below the city average, but the focus neighbourhoods are not the only place where lower SES children cluster. Especially in the Rotterdam-other area many children attend schools with equally or even lower average SES than that of schools in the focus neighbourhoods. ${ }^{9}$ In the discussion we explain what this finding means concerning the distribution of policy means. 
Figure 1. Distribution of students according to school SES and NPRZ area
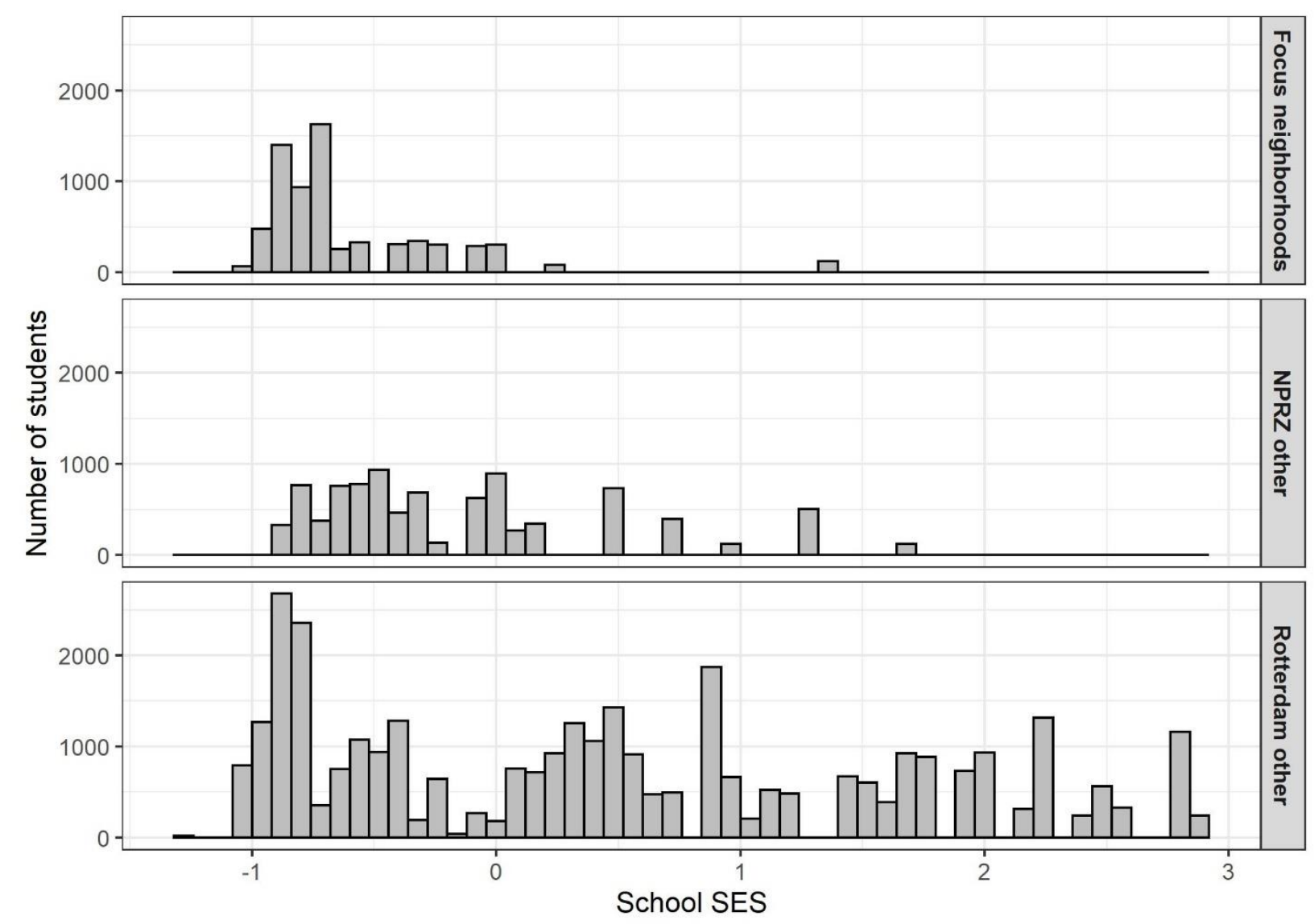

In the final analysis we examine to what extent the effect of parental education has changed over time (Table 3). ${ }^{10}$ For the Rotterdam-other area not a single interaction term is significant (Model 4a), meaning the effect of parental education has been stable between 2008 and 2016. In Rotterdam South we expected the effect to decrease after 2012/2013 due to the educational interventions in the focus neighbourhoods. The only significant interaction term after the start of the NPRZ is in 2015/2016 for middle educated parents, which indicates the difference between low and middle educated parents was smaller in this cohort than in 2012/2013. This trend is, however, not sustained as the interaction for the following cohort (2016/2017) is not significant. Figure 3, which includes the predicted probabilities for educational groups, further illustrates that no trend towards more equality can be observed. For all groups there are some year-to-year fluctuations, but overall predicted probabilities across years are stable. ${ }^{11}$ Interestingly, before the start of the NPRZ the effect of higher professional was weaker $(b=-$ 
4.520 in 2009/2010 and $b=-3.488$ in 2010/2011), but it is not clear what explains this change in effect size. Overall, we conclude that the effect of parental education on secondary school attainment has not become weaker since the start of the NPRZ, thereby rejecting hypothesis $1 .{ }^{12}$

Table 3. Linear multilevel models including interaction effects of parental education and cohort on students' secondary school track at age 15/16 (ISLED scores)

\begin{tabular}{|c|c|c|}
\hline & Model 4a (Rotterdam other) & Model 4b (Rotterdam South) \\
\hline \multicolumn{3}{|c|}{ Cohort (ref. $=2012 / 2013)$} \\
\hline \multirow[t]{2}{*}{$2008 / 2009$} & $1.150^{*}$ & 0.739 \\
\hline & $(0.039,2.261)$ & $(-0.804,2.282)$ \\
\hline \multirow[t]{2}{*}{ 2009/2010 } & 0.233 & 1.251 \\
\hline & $(-0.845,1.312)$ & $(-0.201,2.703)$ \\
\hline \multirow[t]{2}{*}{ 2010/2011 } & 0.135 & -0.158 \\
\hline & $(-0.930,1.200)$ & $(-1.590,1.274)$ \\
\hline \multirow[t]{2}{*}{$2011 / 2012$} & -0.219 & 0.172 \\
\hline & $(-1.295,0.858)$ & $(-1.276,1.619)$ \\
\hline \multirow[t]{2}{*}{$2013 / 2014$} & 0.242 & -0.358 \\
\hline & $(-0.869,1.352)$ & $(-1.890,1.173)$ \\
\hline \multirow[t]{2}{*}{$2014 / 2015$} & 0.403 & 0.479 \\
\hline & $(-0.727,1.533)$ & $(-1.009,1.966)$ \\
\hline \multirow[t]{2}{*}{$2015 / 2016$} & 0.433 & $2.560^{* * *}$ \\
\hline & $(-0.730,1.596)$ & $(1.067,4.053)$ \\
\hline \multirow[t]{2}{*}{$2016 / 2017$} & 1.106 & 1.369 \\
\hline & $(-0.066,2.277)$ & $(-0.169,2.907)$ \\
\hline \multicolumn{3}{|c|}{ Parental education $($ ref. $=$ Low) } \\
\hline \multirow[t]{2}{*}{ Middle } & $2.954^{* * *}$ & $3.585^{* * *}$ \\
\hline & $(1.894,4.015)$ & $(2.151,5.019)$ \\
\hline \multirow[t]{2}{*}{ Higher professional } & $7.033^{* * *}$ & $9.654^{* * *}$ \\
\hline & $(5.624,8.441)$ & $(7.286,12.020)$ \\
\hline \multirow[t]{2}{*}{ University } & $11.040^{* * *}$ & $12.100^{* * * *}$ \\
\hline & $(9.704,12.380)$ & $(8.851,15.360)$ \\
\hline \multicolumn{3}{|l|}{ Interactions } \\
\hline \multirow[t]{2}{*}{ 2008/2009*Middle } & -0.582 & -0.129 \\
\hline & $(-2.107,0.943)$ & $(-2.276,2.017)$ \\
\hline \multirow[t]{2}{*}{ 2009/2010*Middle } & -0.053 & -1.913 \\
\hline & $(-1.540,1.435)$ & $(-3.927,0.100)$ \\
\hline \multirow[t]{2}{*}{ 2010/2011*Middle } & -0.128 & -0.834 \\
\hline & $(-1.599,1.344)$ & $(-2.822,1.154)$ \\
\hline \multirow[t]{2}{*}{ 2011/2012*Middle } & 0.864 & -1.590 \\
\hline & $(-0.607,2.335)$ & $(-3.573,0.393)$ \\
\hline \multirow[t]{2}{*}{ 2013/2014*Middle } & -0.616 & -0.804 \\
\hline & $(-2.106,0.874)$ & $(-2.867,1.259)$ \\
\hline \multirow[t]{2}{*}{ 2014/2015*Middle } & -0.992 & -0.821 \\
\hline & $(-2.501,0.518)$ & $(-2.844,1.201)$ \\
\hline
\end{tabular}




\begin{tabular}{|c|c|c|}
\hline 2015/2016*Middle & $\begin{array}{c}-0.826 \\
(-2.365,0.712)\end{array}$ & $\begin{array}{c}-2.869^{* *} \\
(-4.884,-0.854)\end{array}$ \\
\hline 2016/2017*Middle & $\begin{array}{c}-1.309 \\
(-2.850,0.233)\end{array}$ & $\begin{array}{c}-1.270 \\
(-3.293,0.753)\end{array}$ \\
\hline 2008/2009*Higher professional & $\begin{array}{c}-1.333 \\
(-3.423,0.758)\end{array}$ & $\begin{array}{c}-1.197 \\
(-4.828,2.435)\end{array}$ \\
\hline 2009/2010*Higher professional & $\begin{array}{c}0.231 \\
(-1.766,2.229)\end{array}$ & $\begin{array}{c}-4.478^{*} \\
(-7.963,-0.994)\end{array}$ \\
\hline $2010 / 2011 *$ Higher professional & $\begin{array}{c}0.244 \\
(-1.747,2.236)\end{array}$ & $\begin{array}{c}-3.480^{*} \\
(-6.956,-0.004)\end{array}$ \\
\hline $2011 / 2012 *$ Higher professional & $\begin{array}{c}1.199 \\
(-0.714,3.112)\end{array}$ & $\begin{array}{c}-1.670 \\
(-4.959,1.620)\end{array}$ \\
\hline 2013/2014*Higher professional & $\begin{array}{c}-0.005 \\
(-1.937,1.926)\end{array}$ & $\begin{array}{c}-0.839 \\
(-4.159,2.480)\end{array}$ \\
\hline $2014 / 2015 *$ Higher professional & $\begin{array}{c}0.213 \\
(-1.705,2.132)\end{array}$ & $\begin{array}{c}-2.580 \\
(-5.936,0.776)\end{array}$ \\
\hline 2015/2016*Higher professional & $\begin{array}{c}-0.835 \\
(-2.770,1.100)\end{array}$ & $\begin{array}{c}-2.346 \\
(-5.482,0.790)\end{array}$ \\
\hline 2016/2017*Higher professional & $\begin{array}{c}-0.277 \\
(-2.201,1.647)\end{array}$ & $\begin{array}{c}-1.401 \\
(-4.604,1.802)\end{array}$ \\
\hline 2008/2009*University & $\begin{array}{c}0.347 \\
(-1.635,2.329)\end{array}$ & $\begin{array}{c}-2.672 \\
(-7.553,2.208)\end{array}$ \\
\hline 2009/2010*University & $\begin{array}{c}-0.095 \\
(-2.007,1.818)\end{array}$ & $\begin{array}{c}-0.892 \\
(-5.719,3.934)\end{array}$ \\
\hline 2010/2011*University & $\begin{array}{c}0.089 \\
(-1.800,1.978)\end{array}$ & $\begin{array}{c}1.211 \\
(-3.604,6.027)\end{array}$ \\
\hline 2011/2012*University & $\begin{array}{c}0.142 \\
(-1.709,1.993)\end{array}$ & $\begin{array}{c}-1.967 \\
(-6.385,2.452)\end{array}$ \\
\hline 2013/2014*University & $\begin{array}{c}0.420 \\
(-1.404,2.245)\end{array}$ & $\begin{array}{c}0.575 \\
(-4.066,5.216)\end{array}$ \\
\hline 2014/2015*University & $\begin{array}{c}-0.268 \\
(-2.063,1.527)\end{array}$ & $\begin{array}{c}-0.227 \\
(-4.501,4.046)\end{array}$ \\
\hline 2015/2016*University & $\begin{array}{c}-0.516 \\
(-2.346,1.315)\end{array}$ & $\begin{array}{c}-1.499 \\
(-5.749,2.752)\end{array}$ \\
\hline 2016/2017*University & $\begin{array}{c}-1.601 \\
(-3.424,0.222)\end{array}$ & $\begin{array}{c}-0.108 \\
(-4.253,4.038)\end{array}$ \\
\hline Constant & $\begin{array}{c}43.370^{* * *} \\
(41.810,44.920)\end{array}$ & $\begin{array}{c}40.430^{* * *} \\
(38.440,42.410)\end{array}$ \\
\hline Observations & 33,641 & 16,346 \\
\hline Log Likelihood & $-132,916$ & $-65,676$ \\
\hline Variance school level & 6.97 & 5.24 \\
\hline Variance school-year level & 1.12 & 2.13 \\
\hline Variance individual level & 156.23 & 179.37 \\
\hline
\end{tabular}

Note: effects of other individual and school variables are not reported here, but are included in the models (see Table 1). ${ }^{*} \mathrm{p}<0.05^{* *} \mathrm{p}<0.01{ }^{* * *} \mathrm{p}<0.001$ 
Figure 2. Predicted ISLED scores for the Rotterdam South population (Model 4b)
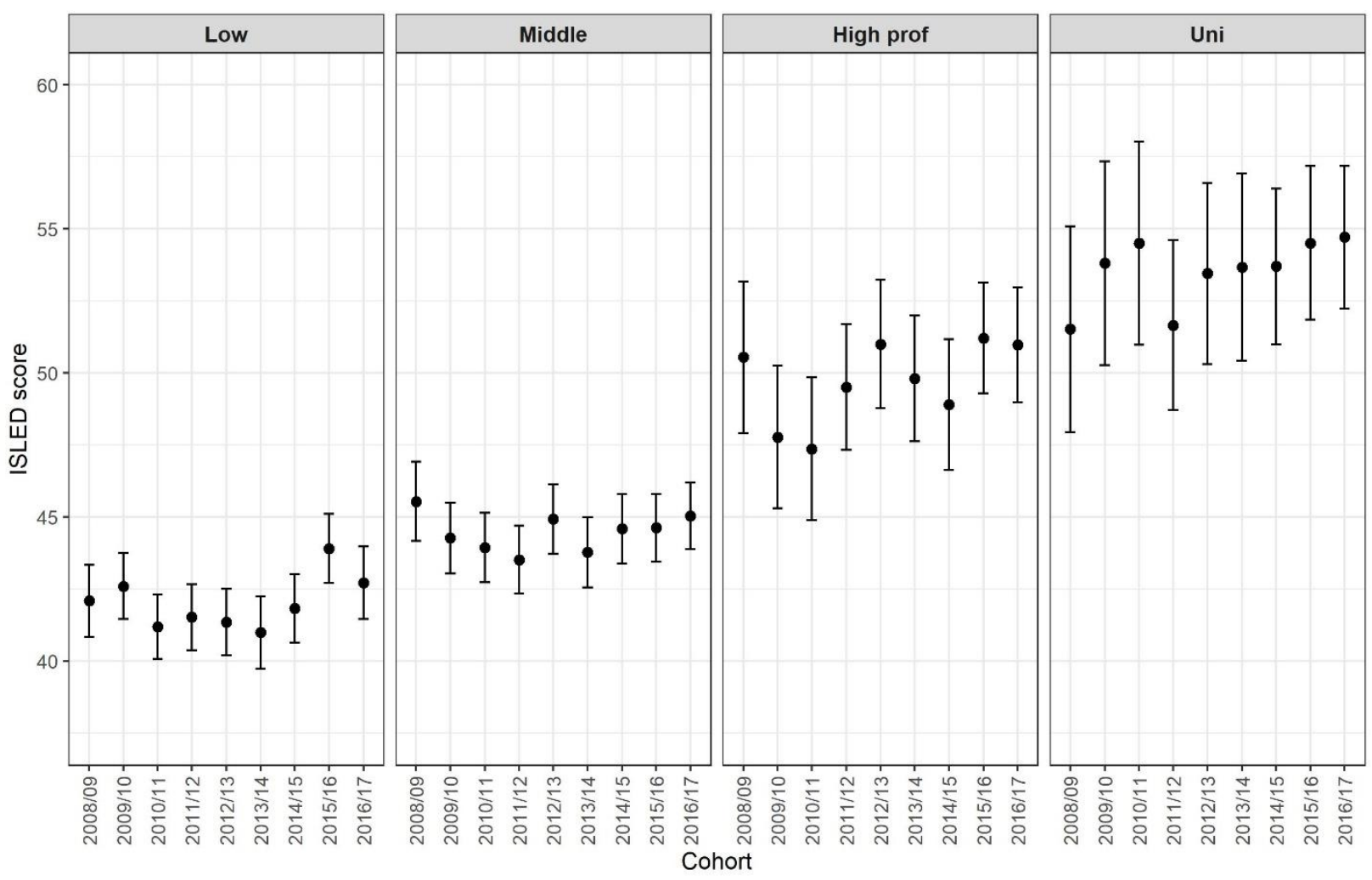

\section{Conclusion and discussion}

This study examined how educational mobility has developed in the context of a major urban policy that aims at reducing social inequality. Following the policy choices of the program, we also studied whether living in the 'focus neighbourhoods' provides an additional disadvantage to educational attainment and to what extent schools are relevant in this regard. Register data on the individual, school and area level were used to empirically investigate these issues.

The first main finding is that we found no evidence that the influence of parental education on secondary school attainment has decreased in Rotterdam South since the start of the NPRZ. We expected that the interventions in the Children's Zone would reduce inequality in educational attainment, but this does not seem to be the case. Three explanations can be offered for this result. First, the extended school time might not contribute to better educational outcomes among children in the Children's Zone. Schools have almost full autonomy in how 
they use this additional time, which leads to considerable variation in activities. Thus, there is no clear aligned program in which interventions are implemented that have a clear theoretical link to better educational outcomes and that are supported by previous research. Second, the national teacher crisis might have prevented schools from attracting high-quality teachers (see Inspectorate of Education, 2019), while studies indicate that having such teachers is an important aspect of improving achievement amongst disadvantaged children (e.g. Dobbie and Fryer, 2011). Schools like those in the focus neighbourhoods, with a low SES and high non-native population, already tend to attract teachers that are less experienced and less effective in teaching (Steele et al., 2015). The lack of high-quality teachers has probably negatively affected the level of classroom instruction, which is an important mechanism that leads to better educational outcomes (Thrupp et al., 2002). Third, we only investigated four cohorts that have been part of the NPRZ. It might be too early to detect any effects that reduce inequality in educational attainment, as effectively implementing such a large program can take quite some time.

Our second main finding is that there appears to be no mediation by school characteristics of an 'focus neighbourhoods' area effect. It may not be very surprising that we did not find this area effect. The focus neighbourhoods are places where disadvantage is concentrated, but the three-category distinction of 'focus neighbourhoods', 'NPRZ other' and 'Rotterdam other' is probably not specific enough to detect an area effect. We note here that neighbourhood effects tend to be non-existent or modest in the Dutch context, which does not only pertain to educational attainment (Kuyvenhoven and Boterman, 2020; Sykes and Musterd, 2011) but also to income (e.g. Troost et al., 2021).

We did find substantial school effects on secondary school attainment, especially relating to school stability and school SES. These effects, in particular the effect of school SES, should be interpreted with caution though. School 'effects' can arise from selection into schools instead of representing an influence of the school climate itself (Thrupp et al., 2002; van Ewijk and Sleegers, 2010). When parents are strongly motivated to have their children perform well in school, they might be inclined to send their children to higher SES schools since school SES and ethnic composition can serve as proxies for school quality (Boterman, 2019). Children who receive more support at home and are more inclined to perform may therefore tend to go to higher SES schools. Also, since we were not able to take prior achievement of students into 
account, this might lead to an overestimation of a school effect: students in different schools may have differed in cognitive capacities to begin with (see van Ewijk and Sleegers, 2010).

The school effects do, however, suggest schools play a role in educational attainment and therefore the policy choice to allocate financial means within the NPRZ to schools seems appropriate. We observed no direct negative 'effect' of living in the focus neighbourhoods. This area does include multiple lower SES schools, which explains why educational attainment tends to be lower independent of individual characteristics. On the other hand, lower SES schools are also located in other parts of Rotterdam South and the rest of Rotterdam and the number of students in these schools are substantial (see Figure 2). If the school SES is an important characteristic through which inequality is sustained, policy means should be distributed on this basis. The NPRZ does so in an indirect way, by first selecting the focus neighbourhoods and then providing additional funds to schools in these neighbourhoods. However, from a perspective of distributional justice, it might make more sense to allocate the means directly based on school SES and other relevant characteristics, since there seems to be no additional disadvantage from only living in the focus neighbourhoods (cf. Dol et al., 2019).

We conclude our analysis with some avenues for future research. But before outlining them, we emphasise that this study has not been a direct test of the effectiveness of the Children's Zone program. We were interested in how educational mobility has developed in the context of the NPRZ, against the background of research that shows levels of educational mobility have been quite stable over a period of many decades (Breen and Jonsson, 2005; Timmermans et al., 2018). Our findings are in line with this view of persistent inequality in educational attainment, which raises questions about to what extent large social programs can reduce this inequality. Our study provides a first insight into the potential of the NPRZ to tackle inequality in educational attainment.

Other research approaches are needed to investigate the effectiveness of the NPRZ. Future research should obtain more insight into the qualitative features of the program, such as which activities are organised at which schools. Currently a wide variety of activities exists, including both curricular (e.g. math and language training) and extracurricular ones (e.g. dance and music lessons). It is important to distinguish between the effects of these activities, since some have a more direct theoretical link to educational attainment than others. Thus, the 
theoretical mechanisms behind the NPRZ interventions should be explicated. More experimental methods are also required to assess to what extent exposure to the Children's Zone program leads to better educational outcomes, for example by using propensity score matching to compare students in the Children's Zone to similar students in Rotterdam or other large cities in the Netherlands. 


\section{References}

Boterman, W. R. (2019). The role of geography in school segregation in the free parental choice context of Dutch cities. Urban Studies, 56(15), pp. 3074-3094.

Brännström, L. (2008). Making their mark: The effects of neighbourhood and upper secondary school on educational achievement. European Sociological Review, 24(4), pp. 463-478.

Breen, R., \& Goldthorpe, J. H. (1997). Explaining educational differentials: Towards a formal rational action theory. Rationality and Society, 9(3), pp. 275-305.

Breen, R., \& Jonsson, J. O. (2005). Inequality of opportunity in comparative perspective: Recent research on educational attainment and social mobility. Annual Review of Sociology, 31, pp. $223-243$.

Butler, T., \& Hamnett, C. (2007). The geography of education: Introduction. Urban Studies, 44(7), pp. 1161-1174.

Carter, P. L. (2003). “Black” cultural capital, status positioning, and schooling conflicts for lowincome African American youth. Social Problems, 50(1), pp. 136-155.

Cook, T. D. (2003). The case for studying multiple contexts simultaneously. Addiction, 98, pp. $151-155$.

Custers, G. (2021). The new divided city: Class transformation, civic participation and neighbourhood context. Rotterdam: Erasmus University Rotterdam.

Custers, G., \& Engbersen, G. (2021). The urban class structure: class change and spatial divisions from a multidimensional class perspective. Urban Geography.

Dobbie, W., \& Fryer Jr, R. G. (2011). Are high-quality schools enough to increase achievement among the poor? Evidence from the Harlem Children's Zone. American Economic Journal: Applied Economics, 3(3), pp. 158-187.

Dol, K., Hoekstra, J., \& Kleinhans, R. (2019). National Program Rotterdam South. Neighbourhood development in a large deprived urban area, Netherlands. RELOCAL Case Study $N^{\circ}$ 20/33. Joensuu: University of Eastern Finland.

El Hadioui, I. (2011). Hoe de straat de school binnendringt: Denken vanuit de pedagogische driehoek van de thuiscultuur, de schoolcultuur en de straatcultuur. Utrecht: APS.

Inspectorate of Education. (2019). Staat van het Onderwijs 2019. Utrecht: Inspectorate of Education. 
Jencks, C., \& Mayer, S. E. (1990). The social consequences of growing up in a poor neighborhood, in: L. E. Lynn \& M. G. McGeary (Eds.), Inner-city poverty in the United States, pp. 111-186. Washington: National Academy Press.

Karsten, S. (1994). Policy on ethnic segregation in a system of choice: the case of the Netherlands. Journal of Education Policy, 9(3), pp. 211-225.

Karsten, S., Felix, C., Ledoux, G., Meijnen, W., Roeleveld, J., \& Van Schooten, E. (2006). Choosing segregation or integration? The extent and effects of ethnic segregation in Dutch cities. Education and Urban Society, 38(2), pp. 228-247.

Kauppinen, T. M. (2008). Schools as mediators of neighbourhood effects on choice between vocational and academic tracks of secondary education in Helsinki. European Sociological Review, 24(3), pp. 379-391.

Kruiter, J., Mens, R., Hoogeveen, K., \& Donkers, E. (2020). Procesevaluatie Dagprogrammering Rotterdam Zuid: Zicht op invoering en mogelijkheden in de toekomst. Utrecht: Sardes.

Kuyvenhoven, J., \& Boterman, W. R. (2021). Neighbourhood and school effects on educational inequalities in the transition from primary to secondary education in Amsterdam. Urban Studies, 58(13), pp. 2660-2682.

Leventhal, T., \& Brooks-Gunn, J. (2000). The neighborhoods they live in: The effects of neighborhood residence on child and adolescent outcomes. Psychological Bulletin, 126(2), p. 309.

Meyer, E., \& Van Klaveren, C. (2013). The effectiveness of extended day programs: Evidence from a randomized field experiment in the Netherlands. Economics of Education Review, 36 , pp. $1-11$.

Municipality of Rotterdam. (2011). Zuid Werkt! Nationaal programma Kwaliteitssprong Zuid. Rotterdam: Municipality of Rotterdam.

Nationaal Programma Rotterdam Zuid (NPRZ). (2012). Uitvoeringsplan 2012-2014. Rotterdam: Nationaal Programma Rotterdam Zuid (NPRZ).

Nieuwenhuis, J., \& Hooimeijer, P. (2016). The association between neighbourhoods and educational achievement, a systematic review and meta-analysis. Journal of Housing and the Built Environment, 31(2), pp. 321-347.

Patall, E. A., Cooper, H., \& Allen, A. B. (2010). Extending the school day or school year: A systematic review of research (1985-2009). Review of Educational Research, 80(3), pp. 401-436. 
Plomin, R., DeFries, J. C., Knopik, V. S., \& Neiderhiser, J. M. (2016). Top 10 replicated findings from behavioral genetics. Perspectives on Psychological Science, 11(1), pp. 3-23.

Schröder, H., \& Ganzeboom, H. B. G. (2014). Measuring and modelling level of education in European societies. European Sociological Review, 30(1), pp. 119-136.

Steele, J. L., Pepper, M. J., Springer, M. G., \& Lockwood, J. R. (2015). The distribution and mobility of effective teachers: Evidence from a large, urban school district. Economics of Education Review, 48, pp. 86-101.

Sykes, B., \& Musterd, S. (2011). Examining neighbourhood and school effects simultaneously: What does the Dutch evidence show? Urban Studies, 48(7), pp. 1307-1331.

Thrupp, M., Lauder, H., \& Robinson, T. (2002). School composition and peer effects. International Journal of Educational Research, 37(5), pp. 483-504.

Timmermans, A. C., de Boer, H., Amsing, H. T. A., \& Van Der Werf, M. P. C. (2018). Track recommendation bias: Gender, migration background and SES bias over a 20-year period in the Dutch context. British Educational Research Journal, 44(5), pp. 847-874.

Troost, A. A., van Ham, M., \& Janssen, H. J. (2021). Modelling neighbourhood effects in three Dutch cities: controlling for selection. Applied Spatial Analysis and Policy.

Van de Werfhorst, H. G., \& Mijs, J. J. B. (2010). Achievement inequality and the institutional structure of educational systems: A comparative perspective. Annual Review of Sociology, 36, pp. 407-428.

Van Ewijk, R., \& Sleegers, P. (2010). The effect of peer socioeconomic status on student achievement: A meta-analysis. Educational Research Review, 5(2), pp. 134-150. 


\section{Notes}

[1] In the literature the terms 'neighbourhood' and 'area' effects are used interchangeably, although in general neighbourhood refers to a smaller geographic unit than area. In this study we refer to area effects when it concerns the NPRZ, since this term better denotes the geographic classifications made within the program. Findings from the literature can still be referred to as neighbourhood effects.

[2] We only discuss the extended school time as it is more directly related to educational outcomes.

[3] Since 2019 the number of mandatory hours has increased to ten hours for all schools in the program.

[4] Track recommendation bias refers to the difference between the track level that students should get based on the central examinations and the track level recommended by the teacher.

[5] Due to genetic factors, intergenerational transmission of education can always be expected, even in societies with a high level of equality in opportunity.

[6] Before 2014, the test was first performed followed by the teacher track recommendation. The new system gives teachers more autonomy in deciding on the final track recommendation.

[7] The share of students with a native Dutch background at the school level was also considered as a control variable. The correlation with school SES was, however, above .8, leading to problems of multicollinearity in the analysis. This high correlation clearly indicates the strong relation between ethnic and SES school segregation.

[8] These percentages were calculated by dividing the individual or school-level variance by the total variance.

[9] Because the NPRZ focuses on disadvantage at the school level, and not school SES in general, we performed additional analyses with two variables that represented school disadvantage rather than school SES. These variables were the share of low educated parents at the school level at the share of parents in the lowest quartile of affluence. We found that the effects in Model 3 had a similar direction but were smaller, which is line with the literature that shows that composite SES variables have a larger effect than single indicators (see van Ewijk and Sleegers, 2010). The distributions of these variables across the three NPRZ areas were also highly similar to the distributions shown in Figure 2.

[10] The Supplemental Material contains a description of how absolute mobility rates have changed between cohorts at the start of the NPRZ and the most recent ones.

[11] We performed the same analyses for the population in the focus neighbourhoods and the NPRZ-other area and found similar results (no significant trends towards more equality). A 
closer examination of ISLED scores among children with low-educated and middleeducated parents suggests that, in contradiction to hypothesis 1, their trend was more clearly upwards in the NPRZ-other area than in the focus neighbourhoods since the start of the NPRZ (see Supplemental Material).

[12] Robustness checks for all models were performed by conducting several multilevel logistic analyses with the categories as binary response variables. The four categories were compared to each other, taking a different reference category for each analysis. In another analysis, the LPV and UPV tracks were grouped together and compared to the SGS and preuniversity tracks grouped together. Although we found some minor variations in the significance of the interaction terms in Models $4 \mathrm{a}$ and $4 \mathrm{~b}$, overall the main conclusion holds: the effect of parental education is stable over time. 